\title{
A new family of cermets: chemically complex but microstructurally simple
}

\author{
A. G. de la Obra ${ }^{1}$, M. A. Avilés ${ }^{1}$, Y. Torres ${ }^{2}$, E. Chicardi ${ }^{3}$ and F. J. Gotor ${ }^{1}$ \\ ${ }^{1}$ Instituto de Ciencia de Materiales de Sevilla (CSIC-US), 41092 Sevilla, Spain \\ ${ }^{2}$ Departamento de Ingeniería Mecánica y de los Materiales y del Transporte, Universidad de \\ Sevilla, 41092 Sevilla, Spain \\ ${ }^{3}$ Departamento de Ingeniería Metalúrgica y Materiales, Universidad Técnica Federico Santa \\ María, Valparaiso 1680, Chile
}

\begin{abstract}
Cermets based on $\operatorname{Ti}(\mathrm{C}, \mathrm{N})$ have interesting properties, such as high wear resistance, high chemical stability and good mechanical strength at high temperature, but to become a viable alternative to cemented carbides, the fracture toughness and damage tolerance must be significantly improved. Complete solid-solution cermets (CSCs) have been proposed to further improve the mechanical properties of these materials. However, to develop this family of cermets with a high level of quality and reliability, using pre-fabricated complex carbonitrides is necessary instead of unalloyed mixtures as the raw ceramic material. A mechanochemical process called mechanically induced self-sustaining reaction (MSR) is suitable to obtain these complex carbonitrides with high stoichiometric control. On the other hand, high entropy alloys (HEAs), which can also be obtained by mechanochemical processes, are a good candidate to replace the current binder phase in cermets because they exhibit high strength and ductility at high temperature and good resistance to both wear and corrosion. In this work, a new family of CSCs based on $(\mathrm{Ti}, \mathrm{Ta}, \mathrm{Nb}) \mathrm{C}_{\mathrm{x}} \mathrm{N}_{1-\mathrm{x}}$ with HEAs belonging to the $\mathrm{Fe}-$ Co-Ni-Cr-Mn-V system as the binder phase is developed by mechanochemical processes. With only two constituent phases, these cermets have a simple microstructure but a high compositional complexity because both the ceramic and binder phases are complex solid solutions with at least five components.
\end{abstract}




\section{Introduction}

Cemented carbide cutting tools (based on WC) are widely used for room-temperature machining due to their exceptional toughness and damage tolerance under cyclic loadings. However, they fail to meet the requirements of the most demanding applications, such as high-speed machining and difficult-to-cut materials, because of their lack of chemical stability and oxidation resistance. At the high temperature reached at the tool/chip interface during use $[1,2]$, wear diffusion can lead to the premature failure of the cutting tool if accompanied by additional wear due to oxidation. Moreover, the EU has classified tungsten as a critical raw material due to its current availability. For all these reasons, the search for alternatives to cemented carbides is presently an important area of research.

Cermets (based on $\operatorname{Ti}(\mathrm{C}, \mathrm{N})$ ) have drawn increasing attention in the machining industry because they possess high wear resistance, high chemical stability and good mechanical strength at high temperature $[3,4]$. Nevertheless, to become a viable alternative to cemented carbides, the fracture toughness and the damage tolerance of cermets must be significantly improved. Thus far, efforts to improve their mechanical properties have mainly been focused on modifying the chemical composition and microstructure of the ceramic component by carefully choosing secondary carbide additives or/and using ultrafine- or nano-Ti(C,N) powders $[5,6]$. Note that when secondary carbides are added to cermets, the ceramic particles develop the characteristic core-rim microstructure via a dissolution-reprecipitation mechanism during the liquid-phase sintering process. The core is the undissolved original $\mathrm{Ti}(\mathrm{C}, \mathrm{N})$ particle, and the rim is a newly formed carbonitride solid solution phase containing $\mathrm{Ti}$ and the other transition metals introduced as single carbides [7]. Because this rim phase is responsible for the good mechanical behavior of cermets, some authors have proposed that the only way of approaching the toughness values of cemented carbides is to develop so-called complete solid solution cermets (CSCs), in which the ceramic particles are composed of only a single homogeneous solid solution phase [8].

Manufacturing CSCs is a complicated task because it requires complex carbonitrides as the ceramic raw material, which first must be correctly synthesized. However, in previous works, a mechanochemical process called mechanically induced self-sustaining reaction (MSR) has been proven to yield homogeneous carbonitride solid solution powders $[9,10]$. This method exploits the strong exothermic character of carbonitride formation from the 
elemental mixtures to promote self-propagating reactions by the mechanical energy supplied by high-energy ball mills. More recently, MSR has been successfully integrated into the powder metallurgy process for the development of CSCs $[11,12]$.

Less attention has been paid to improving the mechanical properties of cermets by altering the binder phase, which is, in fact, the phase that ultimately provides toughness and cohesion to the material. The binder is generally composed of $\mathrm{Ni}, \mathrm{Co}$ or $\mathrm{Co}-\mathrm{Ni}$ alloys. Only in a few cases has the metallic phase been modified by introducing other alloying elements. For example, $\mathrm{Cr}$ is added when improving the corrosion resistance is required [13]. The complete replacement of $\mathrm{Co}$ and $\mathrm{Ni}$ by other metal alloys, such as $\mathrm{Fe}-\mathrm{Cr}$ or $\mathrm{Fe}-\mathrm{Mn}[14,15]$, has been occasionally proposed to offer a cheaper and nontoxic alternative, among other reasons. The use of ternary Fe-Co-Ni alloys as the binder phase in cemented carbides has been suggested as a promising alternative to Co [16]. Broadly, cemented carbides with these binder alloys possess improved toughness and fatigue resistance but lower hardness and Young's modulus.

Recently, high entropy alloys (HEAs) have been postulated to replace current cermet binders [17-19]. These alloys are solid solutions composed of at least five major metal elements in equal or near equal atomic percentages with simple bcc or fcc structure [20]. The properties of HEAs are superior to those of conventional alloys, including high strength and ductility at high temperature and good resistance to wear and corrosion, which perfectly comply with the working requirements for cermets in machining operations. Many HEAs have been described in the literature [20], but as a first approximation, it is logical to propose alternative binders containing a majority of metallic elements that have already been used in conventional binders, either as the primary elements (Co, Ni) or incorporated in minor proportions ( $\mathrm{Cr}, \mathrm{Fe}, \mathrm{V}, \mathrm{Mo}$, etc.), to enhance their properties and processability.

The first step of the overall powder metallurgical (PM) process for manufacturing cermets involves mixing the different powder components (i.e., the ceramic and binder phases). The preferable way to prepare HEAs is melt processing [21-26], such as arc melting and casting, but the need to use powders in PM processes makes mechanical alloying (MA) more suitable. Mechanical alloying is widely recognized as a low-cost and high-efficiency powder processing route able to synthesize homogeneous alloys and nonequilibrium materials [27]. In several studies, HEA powders have already been successfully obtained through MA by choosing the proper milling conditions $[28,29]$. 
This work is an exploratory study on the feasibility of manufacturing CSCs using HEAs as the binder phase. These cermets will have a simple microstructure consisting of only two single phases, which in turn possess a high chemical complexity because they are solid solutions with high numbers of components. A ternary carbonitride solid solution with the nominal chemical composition $\mathrm{Ti}_{0.8} \mathrm{Ta}_{0.1} \mathrm{Nb}_{0.1} \mathrm{C}_{0.5} \mathrm{~N}_{0.5}$ was chosen as the ceramic phase. This stoichiometry was selected on the basis of previous studies that showed that improved oxidation resistance in CSCs based on this ceramic component [30,31]. Meanwhile, two different HEAs were nominated as potential candidates, CoCrFeMnNi and CoCrFeNiV. The CoCrFeMnNi alloy is one of the most extensively studied HEAs [21-25,28], and it has been shown to have a single fcc disordered solid solution phase. However, there are few reports on the CoCrFeNiV alloy [25], although the addition of $\mathrm{V}$ into different HEAs has been shown to usually induce the formation of ordered or intermetallic phases [26]. Special attention was paid to the stability of HEAs after the liquid phase sintering as alloys containing elements with varying melting temperatures can exhibit segregation and inhomogeneity after solidification. A preliminary characterization of the microstructure and mechanical properties of CSCs developed was performed.

\section{Material and methods}

Milling processes played an important role in this work because the ceramic and binder phases were previously synthesized by MSR and MA methods, respectively. Furthermore, mixing and homogenizing both phases to obtain the powdered cermet was conducted by classical mechanical milling (MM) in dry conditions. The global flowchart outlining the pertinent steps for manufacturing CSCs is provided in Fig. 1. Ti powder (99\% purity, <325 mesh, Strem Chemicals), Ta powder (99.6\% purity, <325 mesh, Alfa-Aesar), Nb powder (99.8\% purity, <325 mesh, Alfa-Aesar), C powder (as graphite, <270 mesh, Fe $<0.4 \%$, Merck), Co powder (99.8\% purity, <100 mesh, Strem Chemicals), Cr powder (99\% purity, <100 mesh, Strem Chemicals), Fe powder (99.9\% purity, <10 $\mu \mathrm{m}$, Aldrich), Mn powder (99.5\% purity, <325 mesh, Strem Chemicals), Ni powder (99.9\% purity, <300 mesh, Strem Chemicals), V powder (99.5\% purity, <325 mesh, Strem Chemicals) and $\mathrm{N}_{2}$ gas $\left(\mathrm{H}_{2} \mathrm{O}\right.$ and $\mathrm{O}_{2}<3$ ppm, Air Liquide) were used as the raw materials to develop the CSCs.

To synthesize the ceramic phase with a nominal composition of $\mathrm{Ti}_{0.8} \mathrm{Ta}_{0.1} \mathrm{Nb}_{0.1} \mathrm{C}_{0.5} \mathrm{~N}_{0.5}$, $44.6 \mathrm{~g}$ stoichiometric powder mixture containing elemental $\mathrm{Ti}, \mathrm{Ta}, \mathrm{Nb}$ and $\mathrm{C}$ together with 13 
stainless steel balls $(\mathrm{d}=20 \mathrm{~mm}, \mathrm{~m}=32.6 \mathrm{~g})$ were placed in a tempered steel vial $(300 \mathrm{ml}$ in volume) and milled using a planetary ball mill (Pulverisette 4, Fritsch) at a spinning rate of $400 \mathrm{rpm}$ under $6 \mathrm{~atm} \mathrm{~N}_{2}$. The planetary mill was modified to enable monitoring the MSR by continuously measuring the pressure inside the vial. When the carbonitride solid solution formed, which is an exothermic reaction, the temperature increased, which consequently increased the total pressure. An ignition time, i.e., the critical milling time required to induce the MSR process, of 36 min was determined from the spike in the recorded time-pressure data. After ignition, the milling was continued for $60 \mathrm{~min}$ to ensure full conversion and homogenization. The CoCrFeMnNi (HEA1) and CoCrFeNiV (HEA2) alloys were obtained by MA from elemental powder blends in equiatomic ratios using the same P4 planetary mill. For both alloys, 50 g powder mixture, 15 stainless steel balls with diameters of $20 \mathrm{~mm}$, a $300 \mathrm{ml}$ tempered steel vial, a spinning rate of $400 \mathrm{rpm}$ and $6 \mathrm{~atm} \operatorname{Ar}\left(\mathrm{H}_{2} \mathrm{O}<3\right.$ and $\mathrm{O}_{2}<2 \mathrm{ppm}$, Linde $)$ were used. The MA process was carried out for $10 \mathrm{~h}$, stopping for $30 \mathrm{~min}$ every $2 \mathrm{~h}$ milling to prevent excessive overheating. Subsequently, the two different powdered cermets (CERHEA1 and CER-HEA2) were obtained by dry milling mixtures with 80 wt.\% of the carbonitride ceramic phase and $20 \mathrm{wt} \%$ of the corresponding HEA in a planetary ball mill (Pulverisette 7, Fritsch). For each alloy, $6 \mathrm{~g}$ of the powder mixture and 7 stainless steel balls $(\mathrm{d}=15 \mathrm{~mm}, \mathrm{~m}=13.7 \mathrm{~g}$ ) were put into a $45 \mathrm{ml}$ tempered steel vial and milled for $1 \mathrm{~h}$ at a spinning rate of $400 \mathrm{rpm}$ under 6 atm Ar. Powdered cermets with $1.8 \mathrm{wt} \%$ graphite as an additive were also prepared by dry milling (CER-HEA1-C and CER-HEA2-C). The powdered cermets were then shaped using a uniaxial press ( 2 tons, 5 min) and compacted by cold isostatic pressing (200 MPa, $10 \mathrm{~min}$ ). The green bodies were sintered at temperatures between $1500{ }^{\circ} \mathrm{C}$ and $1575^{\circ} \mathrm{C}$ for 60 min under flowing Ar atmosphere in a horizontal tubular furnace (RTH-180-50-1H, AGNI) to obtain cylindrical cermets $13 \mathrm{~mm}$ in diameter and $9 \mathrm{~mm}$ in height.

The carbon and nitrogen content of the carbonitride phase synthesized by MSR was obtained with an elemental analyzer (model Flash EA1112 CHNS-O, Thermo Finnigan).

X-ray diffraction (XRD) patterns were obtained using a PANalytical X'Pert Pro instrument equipped with a $\theta / \theta$ goniometer, a $\mathrm{Cu} \mathrm{K} \alpha$ radiation source $(40 \mathrm{kV}, 40 \mathrm{~mA})$, a secondary $\mathrm{K}_{\beta}$ filter and an $\mathrm{X}^{\prime}$ Celerator detector. The diffraction patterns were obtained by scanning from $20^{\circ}$ to $140^{\circ}(2 \theta)$ in the step-scan mode with $0.03^{\circ}$ steps and a counting time of 300 s/step. For the sintered cermets, the XRD patterns were obtained once specimens were 
crushed and reduced to powder by hand-grinding to avoid preferential orientations. The space group symmetry and the lattice parameters were calculated from the complete set of peaks in the XRD pattern using the FULLPROF Suite free software, containing the DICVOL, WinPLOTR and FullProf computer programs [32]. Scanning electron microscopy (SEM) images of polished surfaces were obtained on a Hitachi S-4800 field emission SEM in secondary electron mode at an acceleration voltage of $2 \mathrm{kV}$. The transition metal contents in both the ceramic and binder phases were measured by X-ray energy dispersive spectrometry (XEDS) with a detector coupled to the SEM using an acceleration voltage of $20 \mathrm{kV}$.

Hardness measurements were carried out on polished surfaces of cermets at an indentation load of $5 \mathrm{kgf}$ (HV5) using a Vickers diamond pyramidal indenter (EMCO Test M4U-025). At least ten indentations were made for each cermet. The fracture toughness, $\mathrm{K}_{\mathrm{IC}}$, was evaluated by the indentation microfracture (IM) method using the crack length produced at the corners of Vickers indentations and the equation from Niihara [33]. This method is proven to give reasonable estimates of $\mathrm{K}_{\mathrm{IC}}$ in cemented carbides up to values of approximately $15 \mathrm{MPam}^{1 / 2}$ with maximum deviations of $20 \%$ compared with fracture toughness data obtained from single-edge-notched-beam specimens [34]. Loads between $10 \mathrm{kgf}$ and $100 \mathrm{kgf}$ (depending on the cermet) were used to produce cracks with at least half the length of the indentation diagonal, which is the minimum length required to obtain $\mathrm{K}_{\mathrm{IC}}$ values independent of the load. The crack lengths were accurately measured using both optical (Epiphot 200, Nikon) and scanning electron microscopy.

\section{Results and discussion}

The XRD diagrams of the ceramic and HEA powders obtained by MSR and MA processes, respectively, are shown in Fig. 2. The XRD pattern of the ceramic phase was consistent with the formation of a complex titanium-tantalum-niobium carbonitride with a cubic structure and the $F m-3 m$ space group. A lattice parameter of 4.3161(6) $\AA$ was calculated for the carbonitride solid solution. This value was analogous to that obtained in a previous work for a carbonitride phase with a similar nominal stoichiometry $\left(\operatorname{Ti}_{0.8} \operatorname{Ta}_{0.2} \mathrm{C}_{0.5} \mathrm{~N}_{0.5}\right)$ also obtained by MSR [11]. Considering the lattice parameters of tantalum and niobium carbides and nitrides, the partial substitution of $\mathrm{Ta}$ by $\mathrm{Nb}$ in the carbonitride cubic lattice was not expected to have a significant effect on the crystal structure. The presence of $\mathrm{Ti}$, $\mathrm{Ta}$ and $\mathrm{Nb}$ in the ceramic phase was confirmed by XEDS-SEM measurements performed in both the 
powder and sintered cermets, as will be discussed later. However, the $\mathrm{C}$ and $\mathrm{N}$ contents obtained by elemental analysis showed that the carbonitride phase was deficient in nitrogen with a chemical formula of $\mathrm{Ti}_{0.8} \mathrm{Ta}_{0.1} \mathrm{Nb}_{0.1} \mathrm{C}_{0.5} \mathrm{~N}_{0.3}$. This result was in agreement with our previous studies on the synthesis of transition metal carbonitrides by MSR [9,35-37], wherein carbonitride phases with $\mathrm{C} / \mathrm{N}$ ratios slightly above the nominal stoichiometry according to the starting mixture were always obtained. Note that carbides and nitrides, and therefore carbonitrides, of groups IV and V transition metals are well known non-stoichiometric compounds with extended homogeneity intervals [38].

The XRD diagrams of both the HEA1 and HEA2 alloys after $10 \mathrm{~h}$ of milling (Fig. 2) showed the formation of complete solid solutions with simple fcc structures. The lattice parameters of the single phases were 3.6032(6) and 3.6115(7) $\AA$ for CoCrFeMnNi and $\mathrm{CoCrFeNiV}$, respectively. The calculated value for $\mathrm{CoCrFeMnNi}$ alloy was in close agreement with the values found in the literature for $\mathrm{CoCrFeMnNi}$ single phase alloys obtained by melting methods [21,24-26]. The larger lattice parameter determined for the $\mathrm{CoCrFeNiV}$ alloy may be the consequence of a greater distortion of the crystal structure when Mn is substituted by V.

The XRD diagrams of the sintered cermets CER-HEA1 and CER-HEA2 are shown in Fig. 3. The diagrams revealed that the reflection lines of the ceramic phase remained essentially at the same $2 \theta$ position as those of the ceramic powder, suggesting no significant compositional modifications during sintering. The calculated lattice parameters were 4.3204(8) $\AA$ and 4.3137(6) $\AA$ for CER-HEA1 and CER-HEA2, respectively, which are practically identical to that obtained previously for the ceramic powder. However, for the binder phase in both cermets, new reflections lines appeared that were associated with the formation of intermetallic compounds upon sintering. In CER-HEA1, the reflections of the CoCrFeMnNi alloy were still observed $(\mathrm{a}=3.6084(8) \AA)$, but others lines were also detected that were consistent with an intermetallic C14 Laves phase with a hexagonal structure $(\mathrm{a}=\mathrm{b}=$ 4.7981(2) $\AA$ and $\mathrm{c}=8.0325(8) \AA$ ) similar to $\mathrm{Fe}_{2} \mathrm{Ti}$ type. In CER-HEA2, the reflection lines of the $\mathrm{CoCrFeNiV}$ alloy were totally absent; instead, new lines were observed that were assigned to a mixture of two intermetallics: a C14 Laves phase with a hexagonal structure $(\mathrm{a}=\mathrm{b}=$ 4.7937(4) $\AA$ and $c=7.7816(8) \AA)$ and a sigma phase with a tetragonal structure $(\mathrm{a}=\mathrm{b}=$ 9.3344(9) $\AA$ and $\mathrm{c}=4.9119(2) \AA$ ). It has been shown that HEAs containing $\mathrm{Cr}$ and $\mathrm{V}$ are prone to sigma phase formation $[26,39]$. 
In previous studies [40,41], the presence of Ti-containing intermetallic compounds was observed in cermets with $\mathrm{Co}$ or $\mathrm{Ni}$ as the binder phase. In the present case, the excessive dissolution of the ceramic particles in the molten alloy during sintering, promoted by the fact of using a non-stoichiometric carbonitride phase and low nitrogen partial pressure, induced the formation of the intermetallics during cooling from the binder saturated in $\mathrm{Ti}, \mathrm{Nb}$ and/or Ta. As could be demonstrated in previous studies [42,43], carbon activity has an important influence on the coarsening of ceramic particles in hardmetals and cermets during liquid phase sintering, as it can affect the particles' solubility in the binder. In this respect, it has been shown that using a carbon-containing binder melt, for example, adding extra carbon as graphite to the starting mixture, reduces the extent of this dissolution and prevents the formation of the undesirable intermetallic phases that damaged the fracture strength and toughness of cermets [41]. Therefore, this same strategy was followed in this work and two new cermets with graphite as an additive were prepared and sintered (CER-HEA1-C and CER-HEA2-C).

The XRD diagrams of these sintered cermets in Fig. 4 clearly show only the reflections corresponding to the carbonitride phase and the fcc HEAs with no intermetallic phases. Moreover, the reflection lines of both the ceramic and binder phases showed very slight shifts, suggesting only minor compositional changes during sintering. The lattice parameters calculated for the carbonitride phase were 4.3297(6) $\AA$ and 4.3268(9) $\AA$ for CER-HEA1-C and CER-HEA2-C, respectively, slightly larger than those found for the cermets without the carbon additive. This result could suggest slightly higher carbon contents for the carbonitride phase and, therefore, partially incorporating the carbon added to the carbonitride structure during sintering. However, note that these small differences in lattice parameters can also be the result of minor variations in $\mathrm{Ti}$, $\mathrm{Ta}$ and/or $\mathrm{Nb}$ contents in the carbonitride phase. Concerning the binder phase, similar lattice parameters for both HEAs were found in CER-

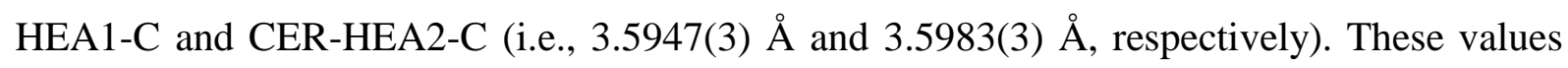
were lower than those calculated after the MA process, which may again be associated with small compositional changes, although note that binder alloys are highly constrained between the ceramic particles.

Representative SEM micrographs of the sintered cermets at different magnifications in Fig. 5 show the characteristic microstructure of CSCs composed of ceramic carbonitride particles without the typical core-rim feature embedded in the binder alloy. This morphology 
confirms that the use of carbonitride solid solutions as the unique ceramic raw material enables achieving this type of cermets. The microstructure of these cermets is considerably less complex than that of conventional cermets and closer to that of relatively straightforward hardmetals. The SEM micrographs show that the ceramic grain size distribution has a bimodal character with submicrometric rounded particles and medium sized faceted particles, which are on average coarser in the CER-HEA 2 cermet. Figure 5 also shows that cermets containing CoCrFeMnNi (CER-HEA1 and CER-HEA1-C) possess higher porosity and an inferior distribution and penetration of the binder phase along the ceramic grain boundaries. These two factors could indicate the lower wettability of this molten alloy than of $\mathrm{CoCrFeNiV}$.

The addition of graphite as an additive does not seem to significantly affect the microstructure of cermets; only a reduction in ceramic particle size and volumetric content of the binder phase was observed, especially in cermets containing CoCrFeNiV (compare in Figure 5 CER-HEA2 and CER-HEA2-C cermets), which was linked less ceramic dissolving into the molten binder during sintering. These results are in agreement with the XRD characterization and suggest a higher solubility of carbonitride particles in the $\mathrm{CoCrFeNiV}$ binder than in CoCrFeMnNi, which may also be responsible for better densification. The higher solubility causes the molten binder to properly wet the ceramic particles, which improves the grain boundary penetration and transport rates that are responsible for grain coarsening and densification.

A careful examination of the SEM micrographs in Figure 5 shows the existence of distinctly shaded regions in the binder phase, which suggest the presence of regions with different chemical compositions because of the alloys' lack of compositional homogeneity (segregation) or the formation of new intermetallic phases during sintering. To extract more information about the distribution of the various constituent elements of the alloys and the nature of the possible intermetallic phases formed, XEDS-SEM mappings and punctual analyses were performed on different areas of the sintered cermets. The mappings are shown in Figures 6-9, and the average chemical compositions of specific areas determined by multiple-point XEDS analyses are listed in Table 1. The terms light grey and grey binders refer to the shades of grey observed within individual SEM micrographs, without suggesting a relationship between them in the various cermets. 
Figure 6 illustrates XEDS-SEM elemental mappings performed on the CER-HEA1 cermet. In the back-scattered image, two different shades (light grey and grey) are visible in the binder phase. The binder region with different shades of grey is difficult to distinguish from the ceramic particles, although the $\mathrm{Co}, \mathrm{Cr}, \mathrm{Fe}, \mathrm{Mn}$ and $\mathrm{Ni}$ mappings allow differentiation. The five alloying elements seem to be homogeneously distributed in both binders. $\mathrm{Ti}, \mathrm{Nb}$ and $\mathrm{Ta}$ mappings show that these elements are also present in the binder phase. Furthermore, Figure 6 clearly shows that the light grey binder possesses a higher $\mathrm{Nb}$ and Ta concentration and, therefore, differences between the two binders may arise from the different elemental contents coming from the aforementioned ceramic dissolution.

Although the accuracy of XEDS measurements and the interference from adjacent phases (lateral and in-depth) must be taken into account, XEDS results (Table 1) confirmed the enrichment of the light grey binder with $\mathrm{Nb}$ and $\mathrm{Ta}$. Note that the $\mathrm{Nb} / \mathrm{Ti}$ and $\mathrm{Ta} / \mathrm{Ti}$ atomic ratios determined for this binder are considerably higher (especially for $\mathrm{Nb}$ ) than the starting nominal ratios. These higher ratios suggest a preferential dissolution of $\mathrm{Nb}$ and $\mathrm{Ta}$ compared with that of $\mathrm{Ti}$ in the molten alloy. Moreover, Fe and Co enrichments were also observed in this binder. After subtracting the potential contribution from adjacent ceramic particles, the XEDS results for the light grey binder showed a chemical composition with a stoichiometry close to 2 in agreement with the $\mathrm{C} 14$ Laves phase with $\mathrm{AB}_{2}$ general formula observed by XRD. On the other hand, the chemical composition of the grey binder was close to that of the $\mathrm{CoCrFeMnNi}$ alloy, with nearly equal atomic contents except for the $\mathrm{Fe}$, which was also enriched in this binder. $\mathrm{Ti}, \mathrm{Nb}$ and $\mathrm{Ta}$ were also detected in this binder, but as the atomic ratios were similar to those found in the carbonitride phase, it was assumed that these elements were detected because of interference from the neighboring ceramic particles. Therefore, it may be reasonable to associate this binder with the fcc alloy as detected by XRD.

The XEDS-SEM mappings (Figure 7) and XEDS results (Table 1) for the CER-HEA2 cermet also showed the existence of two binder phases with clearly different chemical compositions, in which the differences were mainly related to the $\mathrm{Cr}, \mathrm{V}, \mathrm{Nb}$ and $\mathrm{Ta}$ contents. The light grey binder is enriched in $\mathrm{Nb}$ and $\mathrm{Ta}$, but deficient in $\mathrm{Cr}$ and especially in $\mathrm{V}$. As for CER-HEA1, this binder was associated with the C14 Laves phase. However, the grey binder has a chemical composition approaching that of the CoCrFeNiV alloy, but clearly enriched with $\mathrm{Cr}$ and $\mathrm{Fe}$. Again, the detection of $\mathrm{Ti}, \mathrm{Nb}$ and $\mathrm{Ta}$ in this binder can be caused by interference from the adjacent ceramic particles. This binder may correspond to the sigma 
phase observed in the XRD pattern in Figure 3. The absence of the CoCrFeNiV alloy could suggest that most of the alloy was transformed into these new intermetallics because of the higher ceramic dissolution, as previously mentioned, thus allowing for better densification.

The XEDS mappings (Figure 8) and XEDS results (Table 1) for the CER-HEA1-C cermet confirmed that the addition of graphite was effective in reducing the dissolution of ceramic particles into the molten alloy. No binder regions enriched in $\mathrm{Nb}$ and $\mathrm{Ta}$ were observed, and the detected $\mathrm{Ti}, \mathrm{Nb}$ and $\mathrm{Ta}$ contents were in agreement with the atomic ratios in the carbonitride phase, and they were therefore attributed to the interference of adjacent ceramic particles. The binder with the light grey color was deficient in Mn and Cr. In contrast, small darker grey binder areas were observed, which possessed a significant enrichment in $\mathrm{Cr}$. This $\mathrm{Cr}$ segregation might explain the slight shift in the lattice parameter of the $\mathrm{CoCrFeMnNi}$ alloy in this cermet compared with that of the as-obtained alloy after the MA process. Finally, the addition of graphite also succeeded in preventing the ceramic dissolution during sintering in the CER-HEA2-C cermet (Figure 9 and Table 1). The homogeneous distribution of $\mathrm{V}$ shown in the mapping in Figure 9 was the consequence of interference with $\mathrm{Ti} \mathrm{K}_{\beta}$ lines. Furthermore, no evidence of segregation was detected in this cermet's binder, which maintained a homogeneous chemical composition corresponding to the initial $\mathrm{CoCrFeNiV}$ alloy. In summary, XEDS results have shown that the incorporation of $\mathrm{Ti}$ and especially $\mathrm{Nb}$ and Ta into the initial alloys induced the formation of intermetallic compounds.

A preliminary characterization of the mechanical behavior of the sintered cermets, including Vickers hardness and fracture toughness, was conducted, and the results are summarized in Table 2. The hardness values for the cermets containing the CoCrFeNiV alloy were of the same order of magnitude as those reported for CSCs with conventional binders and similar binder contents [41]. However, cermets with $\mathrm{CoCrFeMnNi}$ alloy had considerably lower hardness values, although no significant difference was observed between the microhardnesses of both alloys as measured in powder particles after the MA process (HV0.01 of $88 \pm 13$ and $104 \pm 7$ for CoCrFeMnNi and $\mathrm{CoCrFeNiV}$, respectively). It is therefore possible that this difference was simply the consequence of the poor densification observed in cermets with CoCrFeMnNi alloy.

The fracture toughnesses (Table 2) of the cermets without graphite (CER-HEA1 and CER-HEA-2) were lower than the corresponding cermets with graphite (CER-HEA1-C and CER-HEA-2-C) due to the presence of the intermetallic compounds in the binder. Note that 
the cermet with the lowest $\mathrm{K}_{\mathrm{IC}}$ (CER-HEA-2) was actually the cermet with only intermetallic phases as the binder, as demonstrated by XRD measurements. The addition of graphite prevented the formation of these intermetallics, thus leading to the increase in $\mathrm{K}_{\mathrm{IC}}$. However, the observed increase in $\mathrm{K}_{\mathrm{IC}}$ was lower than expected compared with similar CSCs with conventional binders [41]. Moreover, the increasing $\mathrm{K}_{\mathrm{IC}}$ was accompanied by a decrease in the hardness values because the alloys, which are more ductile than the intermetallic compounds, were acting as the binder phase. The best compromise between hardness and fracture toughness was found for the CER-HEA-2-C cermet $\left(\mathrm{HV} 5=1048\right.$ and $\mathrm{K}_{\mathrm{IC}}=6.8 \mathrm{MPam}^{1 / 2}$ ).

\section{Conclusions}

This work proved that the development of CSCs with HEAs acting as alternative binder is possible because of the mechanochemical processes that enable the synthesis of the constituent phases. The MSR process led to a carbonitride solid solution containing $\mathrm{Ti}, \mathrm{Nb}$ and $\mathrm{Ta}$, and the MA process created single phase HEAs, specifically CoCrFeMnNi and

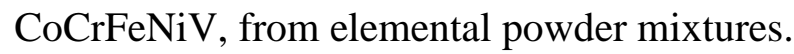

A key factor in achieving the desired CSC material is the strict control of the metallurgical reactions during the liquid phase sintering that can induce segregations in the alloy binder and even the formation of intermetallic phases, which are generally detrimental to the mechanical behavior. Using graphite as a sintering additive was crucial to reducing the extent of the carbonitride ceramic particles dissolved during sintering, which was the main reason for the chemical changes observed in the binder phase. Better densification and mechanical behavior was observed in cermets with the CoCrFeNiV alloy.

Although the hardness and fracture toughness values obtained were lower than expected, the results are promising because both properties should be negatively affected by the poor densification observed, as evidenced by the excessive porosity and poor distribution of the binder phase in the whole cermet specimen. This incomplete densification may be the result of the molten binder's low wettability that has to be improved, for example, by choosing the best alloying elements and their concentration or adding secondary carbides (WC, $\mathrm{Mo}_{2} \mathrm{C}$ ) as in conventional cermets. Moreover, optimizing other key parameters, such as the grain size and chemical composition of the ceramic particles, offers strong motivation for further research. 


\section{Acknowledgments}

This study was supported by the Spanish Government under grant MAT2014-52407$\mathrm{R}$, financed in part by the European Regional Development Fund.

\section{References}

[1] Casas B, Ramis X, Anglada M, Salla JM, Llanes L. Oxidation-induced strength degradation of WC-Co hardmetals. Int J Refract Met Hard Mat 2001;19:303-9.

[2] Abukhshim NA, Mativenga PT, Sheikh MA. Heat generation and temperature prediction in metal cutting: A review and implications for high speed machining. Int J Mach Tools Manuf 2006;46:782-800.

[3] Bolognini S, Feusier G, Mari D, Viatte T, Benoit W. High temperature mechanical behaviour of Ti(C,N)-Mo-Co cermets. Int J Refract Met Hard Mat 1998:16 257-68.

[4] Zhang H, Tang S, Yan J, Hu X. Cutting performance of titanium carbonitride cermet tools. Int J Refract Met Hard Mat 2007;25:440-4.

[5] Kumar BVM, Basu B, Vizintin J, Kalin M. Tribochemistry in sliding wear of TiCN-Nibased cermets. J Mat Res 2008;23:1214-27.

[6] Peng Y, Miao H, Peng Z. Development of TiCN-based cermets: Mechanical properties and wear mechanism. Int J Refract Met Hard Mat 2013;39:78-89.

[7] Ahn SY, Kang S. Formation of core/rim structures in Ti(C,N)-WC-Ni cermets via a dissolution and precipitation process. J Am Ceram Soc 2000;83:1489-94.

[8] Kim JW, Ahn SY, Kang S. Effect of the complete solid-solution phase on the microstructure of Ti(CN)-based cermet. Int J Refract Met Hard Mat 2009;27:224-8.

[9] Córdoba JM, Avilés MA, Sayagués MJ, Alcalá MD, Gotor FJ. Synthesis of complex carbonitride powders $\mathrm{Ti}_{\mathrm{y}} \mathrm{MT}_{1-\mathrm{y}} \mathrm{C}_{\mathrm{x}} \mathrm{N}_{1-\mathrm{x}}(\mathrm{MT}: \mathrm{Zr}, \mathrm{V}, \mathrm{Ta}, \mathrm{Hf})$ via a mechanically induced selfsustaining reaction. J Alloy Compd 2009;482:349-55.

[10]Borrell A, Salvador MD, Garcia-Rocha V, Fernandez A, Chicardi E, Gotor FJ. Spark plasma sintering of $\mathrm{Ti}_{\mathrm{y}} \mathrm{Nb}_{1-\mathrm{y}} \mathrm{C}_{\mathrm{x}} \mathrm{N}_{1-\mathrm{x}}$ monolithic ceramics obtained by mechanically induced self-sustaining reaction. Mater Sci Eng A 2012;543:173-9. 
[11]Chicardi E, Córdoba JM, Sayagués MJ, Gotor FJ. Absence of the core-rim microstructure in $\mathrm{Ti}_{\mathrm{x}} \mathrm{Ta}_{1-\mathrm{x}} \mathrm{C}_{\mathrm{y}} \mathrm{N}_{1-\mathrm{y}}$-based cermets developed from a pre-sintered carbonitride master alloy. Int $\mathrm{J}$ Refract Met Hard Mat 2012;33:38-43.

[12] Córdoba JM, Chicardi E, Gotor FJ. Development of multicomponent-multiphase materials based on $(\mathrm{Ti}, \mathrm{Ta}, \mathrm{Nb}) \mathrm{C}_{\mathrm{x}} \mathrm{N}_{1-\mathrm{x}}$ carbonitride solid solutions. Chem Eng J 2012;192:5866.

[13]Chen S, Xiong WH, Yao ZH, Zhang GP, Chen X, Huang B, Yang QQ. Corrosion behavior of $\mathrm{Ti}(\mathrm{C}, \mathrm{N})-\mathrm{Ni} / \mathrm{Cr}$ cermets in $\mathrm{H}_{2} \mathrm{SO}_{4}$ solution. Int $\mathrm{J}$ Refract Met Hard Mat 2014;47:139-44.

[14] Alvaredo P, Tsipas SA, Gordo E. Influence of carbon content on the sinterability of an FeCr matrix cermet reinforced with TiCN. Int J Refract Met Hard Mat 2013;36:283-8.

[15] Hanyaloglu C, Aksakal B, Bolton JD. Production and indentation analysis of WC/Fe-Mn as an alternative to cobalt-bonded hardmetals. Mater Charact 2001;47:315-22.

[16] Gille G, Bredthauer J, Gries B, Mende B, Heinrich W. Advanced and new grades of WC and binder powder - their properties and application. Int J Refract Met Hard Mat 2000;18:87102.

[17]Zhu G, Liu Y, Ye J. Fabrication and properties of Ti(C,N)-based cermets with multicomponent AlCoCrFeNi high-entropy alloys binder. Mater Lett 2013;113:80-2.

[18]Chen CS, Yang CC, Chai HY, Yeh JW, Chau JLH. Novel cermet material of WC/multielement alloy. Int J Refract Met Hard Mat 2014;43:200-4.

[19]Lin CM, Tsai CW, Huang SM, Yang CC, Yeh JW. New TiC/Co ${ }_{1.5} \mathrm{CrFeNi}_{1.5} \mathrm{Ti}_{0.5}$ cermet with slow TiC coarsening during sintering. JOM 2014;66:2050-6.

[20]Zhang Y, Zuo TT, Tang Z, Gao MC, Dahmen KA, Liaw PK, Lu ZP. Microstructures and properties of high-entropy alloys. Prog Mater Sci 2014;61:1-93.

[21] Cantor B, Chang ITH, Knight P, Vincent AJB. Microstructural development in equiatomic multicomponent alloys. Mat Sci Eng. A 2004;375-377:213-8.

[22] Otto F, Dlouhý A, Somsen Ch, Bei H, Eggeler G, George EP. The influences of temperature and microstructure on the tensile properties of a $\mathrm{CoCrFeMnNi}$ high-entropy alloy. Acta Mater 2013;61:5743-55. 
[23] Tasan CC, Deng Y, Pradeep KG, Yao MJ, Springer H, Raabe D. Composition dependence of phase stability, deformation mechanisms, and mechanical properties of the CoCrFeMnNi high-entropy alloy system. JOM 2014;66:1993-2001.

[24] Laurent-Brocq M, Akhatova A, Perrière L, Chebini S, Sauvage X, Leroy E, Champion Y. Insights into the phase diagram of the $\mathrm{CrMnFeCoNi}$ high entropy alloy. Acta Mater $2015 ; 88: 355-65$.

[25] Salishchev GA, Tikhonovsky MA, Shaysultanov DG, Stepanov ND, Kuznetsov AV, Kolodiy IV, Tortika AS, Senkov ON. Effect of Mn and V on structure and mechanical properties of high-entropy alloys based on CoCrFeNi system. J Alloy Compd 2014;591:1121.

[26] Stepanov ND, Shaysultanov DG, Salishchev GA, Tikhonovsky MA, Oleynik EE, Tortika AS, Senkov ON. Effect of $\mathrm{V}$ content on microstructure and mechanical properties of the CoCrFeMnNiVx high entropy alloys. J Alloy Compd 2015;628:170-85.

[27] Suryanarayana C. Mechanical alloying and milling. Prog Mater Sci 2001;46:1-184.

[28] Ji W, Wang W, Wang H, Zhang J, Wang Y, Zhang F, Fu Z. Alloying behavior and novel properties of $\mathrm{CoCrFeNiMn} \mathrm{high-entropy} \mathrm{alloy} \mathrm{fabricated} \mathrm{by} \mathrm{mechanical} \mathrm{alloying} \mathrm{and} \mathrm{spark}$ plasma sintering. Intermetallics 2015;56:24-7.

[29] Varalakshmi S, Kamaraj M, Murty BS, Processing and properties of nanocrystalline CuNiCoZnAlTi high entropy alloys by mechanical alloying. Mat Sci Eng. A 2010;527: 102730.

[30] Chicardi E, Gotor FJ, Córdoba JM. Enhanced oxidation resistance of Ti(C,N)-based cermets containing Ta. Corros Sci 2014;84:11-20.

[31] Chicardi E, Córdoba JM, Gotor FJ. High temperature oxidation resistance of (Ti,Ta)(C,N)-based cermets. Corros Sci 2016;102:125-36.

[32] Rodriguez-Carvajal J. Full Prof: A program for Rietveld refinement and profile matching analysis of complex powder diffraction patterns. 2013.

[33] Niihara K. A fracture-mechanics analysis of indentation-induced Palmqvist crack in ceramics. J Mater Sci Lett 1983;2:221-3.

[34] Spiegler R, Schmauder S, Sigl L. Fracture toughness evaluation of WC-Co alloys by indentation testing. J Hard Mater 1990;1:158-174. 
[35] Córdoba JM, Sayagués MJ, Alcalá MD, Gotor FJ. Synthesis of titanium carbonitride phases by reactive milling of the elemental mixed powders. J Am Ceram Soc 2005;88:17601764.

[36] Córdoba JM, Sayagués MJ, Alcalá MD, Gotor FJ. Monophasic Nanostructured Powders of Niobium, Tantalum, and Hafnium Carbonitrides Synthesized by Mechanically Induced Self-Propagating Reaction. J Am Ceram Soc 2007;90:381-387.

[37] Córdoba JM, Sayagués MJ, Alcalá MD, Gotor FJ. Monophasic $\mathrm{Ti}_{\mathrm{y}} \mathrm{Nb}_{1-\mathrm{y}} \mathrm{C}_{\mathrm{x}} \mathrm{N}_{1-\mathrm{x}}$ Nanopowders Obtained at Room Temperature by MSR. J Mat Chem 2007;17:650-653.

[38] Gusev AI, Rempel AA, Magerl AJ. Disorder and Order in Strongly Nonstoichiometric Compounds: Transition Metal Carbides, Nitrides and Oxides. Springer-Verlag Berlin Heidelberg; 2001.

[39] Tsai MH, Chang KC, Li JH, Tsai RC, Cheng AH. A second criterion for sigma phase formation in high-entropy alloys. Mater Res Lett 2015;DOI:10.1080/21663831.2015.1121168.

[40] Zackrisson J, Larsson A, Andrén HO. Microstructure of the Ni binder phase in a TiC$\mathrm{Mo}_{2} \mathrm{C}-\mathrm{Ni}$ cermet. Micron 2001;32:707-712.

[41] Chicardi E, Torres Y, Córdoba JM, Hvizdoš P, Gotor FJ. Effect of tantalum content on the microstructure and mechanical behavior of cermets based on $\left(\mathrm{Ti}_{\mathrm{x}} \mathrm{Ta}_{1-\mathrm{x}}\right)\left(\mathrm{C}_{0.5} \mathrm{~N}_{0.5}\right)$ solid solutions. Mater Design 2014;53:435-44.

[42] Borgh I, Hedstrom P, Borgenstam A, Agren J, Odqvist J. Effect of carbon activity and powder particle size on WC grain coarsening during sintering of cemented carbides. Int $\mathbf{J}$ Refract Met Hard Mater 2014;42:30-35.

[43] Zheng Y, Liu WJ, Wang SX, Xiong WH. Effect of carbon content on the microstructure and mechanical properties of $\mathrm{Ti}(\mathrm{C}, \mathrm{N})$-based cermets. Ceram Int 2004;30:2111-2115.

[44] Chicardi E, Torres Y, Sayagués MJ, Medri V, Melandri C, Córdoba JM, Gotor FJ. Toughening of complete solid solution cermets by graphite addition. Chem Eng J 2015;267:297-305. 


\section{FIGURE CAPTIONS}

Figure 1. Global flowchart outlining the different steps for manufacturing CSCs using HEAs as the binder phase.

Figure 2. XRD diagrams of the carbonitride ceramic phase $(\mathrm{Ti}, \mathrm{Ta}, \mathrm{Nb})(\mathrm{C}, \mathrm{N})(\bullet)$ obtained by MSR and the CoCrFeMnNi ( $\mathbf{a})$ and $\mathrm{CoCrFeNiV} \mathrm{( \square )} \mathrm{high} \mathrm{entropy} \mathrm{alloys} \mathrm{synthesized} \mathrm{by} \mathrm{MA.}$

Figure 3. XRD diagrams of the sintered cermets CER-HEA1 and CER-HEA2.

$(\mathrm{Ti}, \mathrm{Ta}, \mathrm{Nb})(\mathrm{C}, \mathrm{N}) ;(\mathbf{\square}) \mathrm{CoCrFeMnNi}$; (O) intermetallic C14 Laves phase; $(\diamond)$ intermetallic C14 Laves phase; $(\diamond)$ sigma phase.

Figure 4. XRD diagrams of the sintered cermets CER-HEA1-C and CER-HEA2-C. (•) $(\mathrm{Ti}, \mathrm{Ta}, \mathrm{Nb})(\mathrm{C}, \mathrm{N}) ;(\mathbf{\square}) \mathrm{CoCrFeMnNi}$ ( $\square) \mathrm{CoCrFeNiV}$.

Figure 5. Representative SEM micrographs at different magnifications (2 kX, $5 \mathrm{kX}$ and 10 kX) of CER-HEA1, CER-HEA2, CER-HEA1-C and CER-HEA2-C cermets.

Figure 6. SEM-XEDS elemental mappings performed on the CER-HEA1 cermet.

Figure 7. SEM-XEDS elemental mappings performed on the CER-HEA2 cermet.

Figure 8. SEM-XEDS elemental mappings performed on the CER-HEA1-C cermet.

Figure 9. SEM-XEDS elemental mappings performed on the CER-HEA2-C cermet. 
Table 1. XEDS analysis performed on different regions of the sintered cermets.

\begin{tabular}{|c|c|c|c|c|c|c|c|c|c|c|}
\hline Cermet & Zone & $\begin{array}{c}\begin{array}{c}\text { Co } \\
\text { (at\%) }\end{array} \\
\end{array}$ & $\begin{array}{c}\begin{array}{c}\mathrm{Cr} \\
(\mathrm{at} \%)\end{array} \\
\end{array}$ & $\begin{array}{c}\begin{array}{c}\text { Fe } \\
(\text { at\%) }\end{array} \\
\end{array}$ & $\begin{array}{c}\text { Mn } \\
\text { (At\%) }\end{array}$ & $\begin{array}{c}\mathrm{Ni} \\
\text { (at\%) }\end{array}$ & $\begin{array}{c}\begin{array}{c}V \\
\text { (at\%) }\end{array} \\
\end{array}$ & $\begin{array}{c}\mathrm{Ti} \\
\text { (at\%) }\end{array}$ & $\begin{array}{c}\mathrm{Nb} \\
\text { (at\%) }\end{array}$ & $\begin{array}{c}\text { Ta } \\
\text { (at\%) } \\
\end{array}$ \\
\hline CER-HEA1 & $\begin{array}{l}\text { ceramic } \\
\text { particles }\end{array}$ & - & - & - & - & - & - & 81.0 & 8.4 & 10.6 \\
\hline CER-HEA1 & $\begin{array}{l}\text { light grey } \\
\text { binder }\end{array}$ & 14.0 & 8.8 & 14.4 & 7.1 & 8.2 & - & 31.5 & 10.1 & 5.9 \\
\hline CER-HEA1 & $\begin{array}{c}\text { grey } \\
\text { binder }\end{array}$ & 13.1 & 15.7 & 20.2 & 13.0 & 14.9 & - & 19.6 & 1.9 & 1.6 \\
\hline CER-HEA2 & $\begin{array}{l}\text { ceramic } \\
\text { particles }\end{array}$ & - & - & - & - & - & - & 85.2 & 7.0 & 7.8 \\
\hline CER-HEA2 & $\begin{array}{l}\text { light grey } \\
\text { binder }\end{array}$ & 15.1 & 8.7 & 18.6 & - & 13.9 & 5.2 & 22.6 & 9.7 & 6.2 \\
\hline CER-HEA2 & $\begin{array}{c}\text { grey } \\
\text { binder }\end{array}$ & 11.3 & 16.2 & 18.6 & - & 11.5 & 12.0 & 25.7 & 2.6 & 2.3 \\
\hline CER-HEA1-C & $\begin{array}{l}\text { ceramic } \\
\text { particles }\end{array}$ & - & - & - & - & - & - & 83.4 & 8.8 & 7.8 \\
\hline CER-HEA1-C & $\begin{array}{l}\text { light grey } \\
\text { binder }\end{array}$ & 18.9 & 10.7 & 26.4 & 12.2 & 17.9 & - & 11.8 & 1.2 & 0.9 \\
\hline CER-HEA1-C & $\begin{array}{l}\text { grey } \\
\text { binder }\end{array}$ & 4.3 & 48.9 & 11.0 & 6.3 & 2.6 & - & 22.9 & 2.0 & 2.0 \\
\hline CER-HEA2-C & $\begin{array}{l}\text { Ceramic } \\
\text { particles }\end{array}$ & - & - & - & - & - & - & 84.3 & 7.9 & 7.8 \\
\hline CER-HEA2-C & $\begin{array}{l}\text { light grey } \\
\text { binder }\end{array}$ & 18.1 & 18.9 & 18.8 & - & 17.5 & 17.4 & 7.5 & 0.9 & 0.9 \\
\hline
\end{tabular}


Table 2. Vickers hardness (HV5) and indentation fracture toughness ( $\left.\mathrm{K}_{\mathrm{IC}}\right)$ of sintered cermets

\begin{tabular}{ccc}
\hline Cermet & HV5 & K $_{\text {IC }}\left(\right.$ MPam $\left.^{1 / 2}\right)$ \\
\hline CER-HEA1 & $928 \pm 92$ & $6.6 \pm 0.3$ \\
CER-HEA2 & $1295 \pm 82$ & $4.0 \pm 0.5$ \\
CER-HEA1-C & $663 \pm 92$ & $7.1 \pm 0.8$ \\
CER-HEA2-C & $1048 \pm 54$ & $6.8 \pm 0.6$ \\
\hline
\end{tabular}


$\mathrm{Ti}(\mathrm{s}), \mathrm{Ta}(\mathrm{s}), \mathrm{Nb}(\mathrm{s}), \mathrm{C}(\mathrm{s}), \mathrm{N},(\mathrm{g}) \quad \mathrm{Fe}(\mathrm{s}), \mathrm{Co}(\mathrm{s}), \mathrm{Ni}(\mathrm{s}), \mathrm{Cr}(\mathrm{s}), \mathrm{Mn}(\mathrm{s})$ or V(s) $1_{\text {MSR }}^{\text {st milling process: }}$ $(\mathbf{T i}, \mathbf{T a}, \mathbf{N b})(\mathbf{C}, \mathbf{N})$ 2 milling process : MA CoCrFeMnNi or CoCrFeNiV $3^{\text {iu }}$ milling process: MM

Powdered cermet

80 wt \% $(\mathrm{Ti}, \mathrm{Ta}, \mathrm{Nb})(\mathrm{C}, \mathrm{N})+20$ wt $\%$ HEA

\author{
$\downarrow$ Molding and compaction \\ Green body \\ $\downarrow$ Sintering \\ Cermet
}

FIGURE 1 


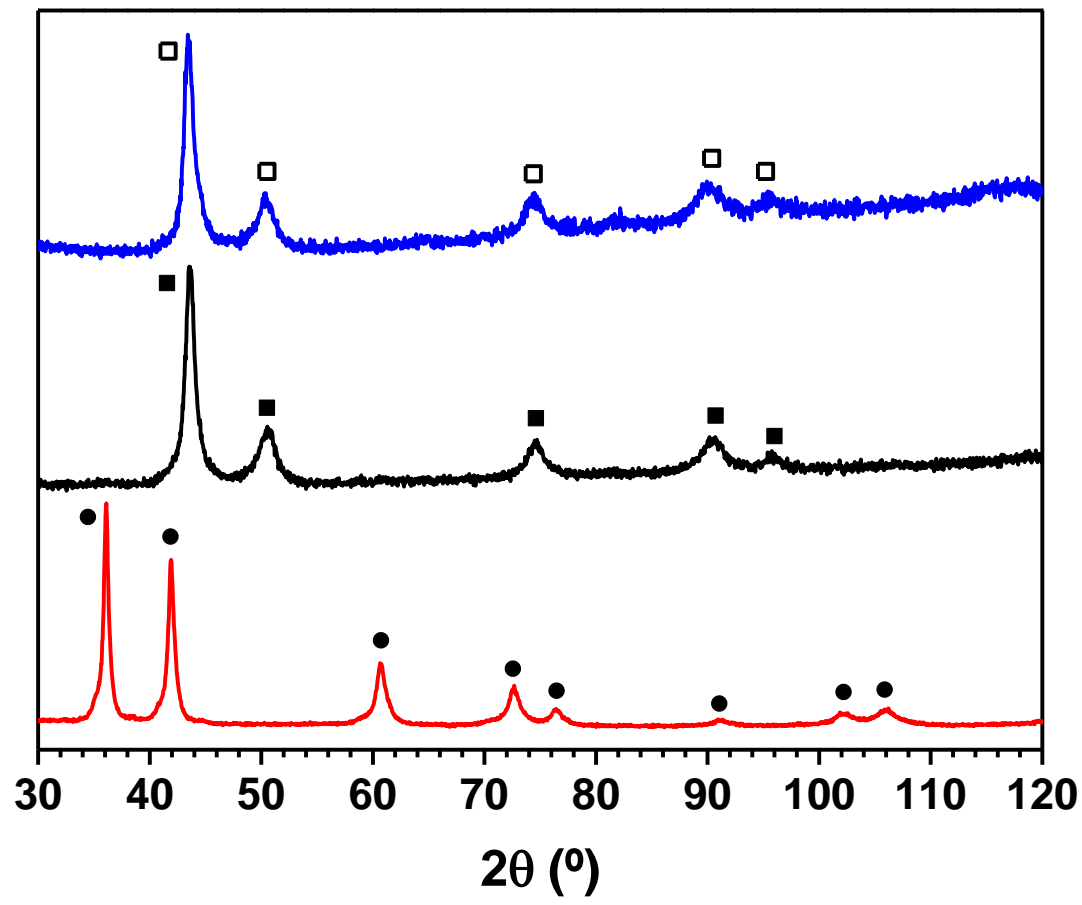

FIGURE 2 


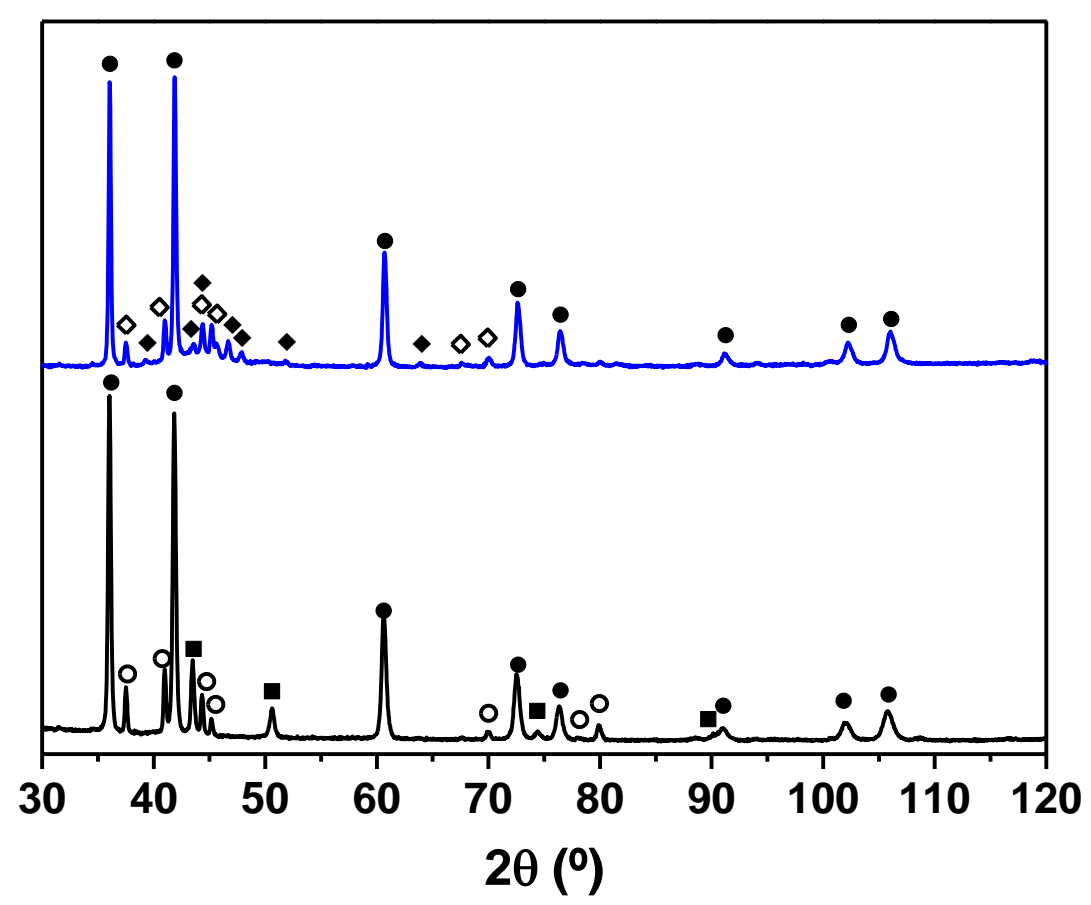

FIGURE 3 


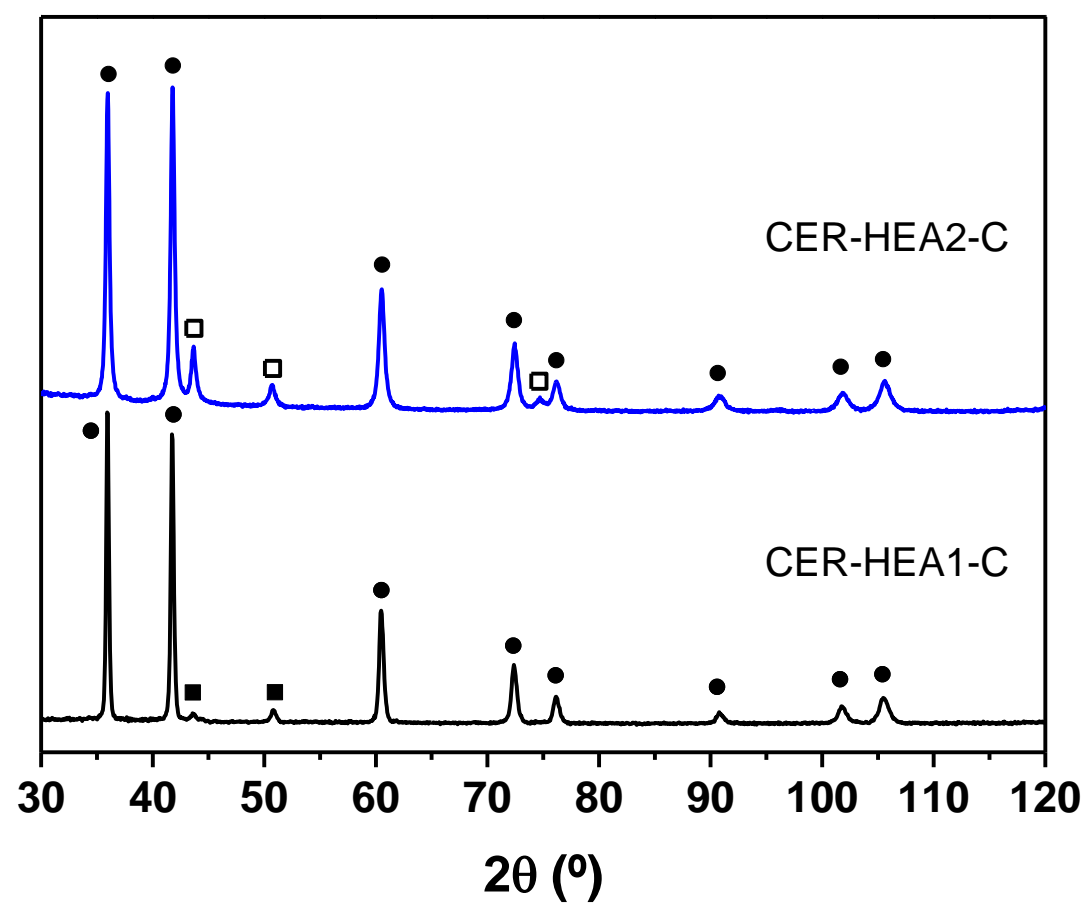

FIGURE 4 


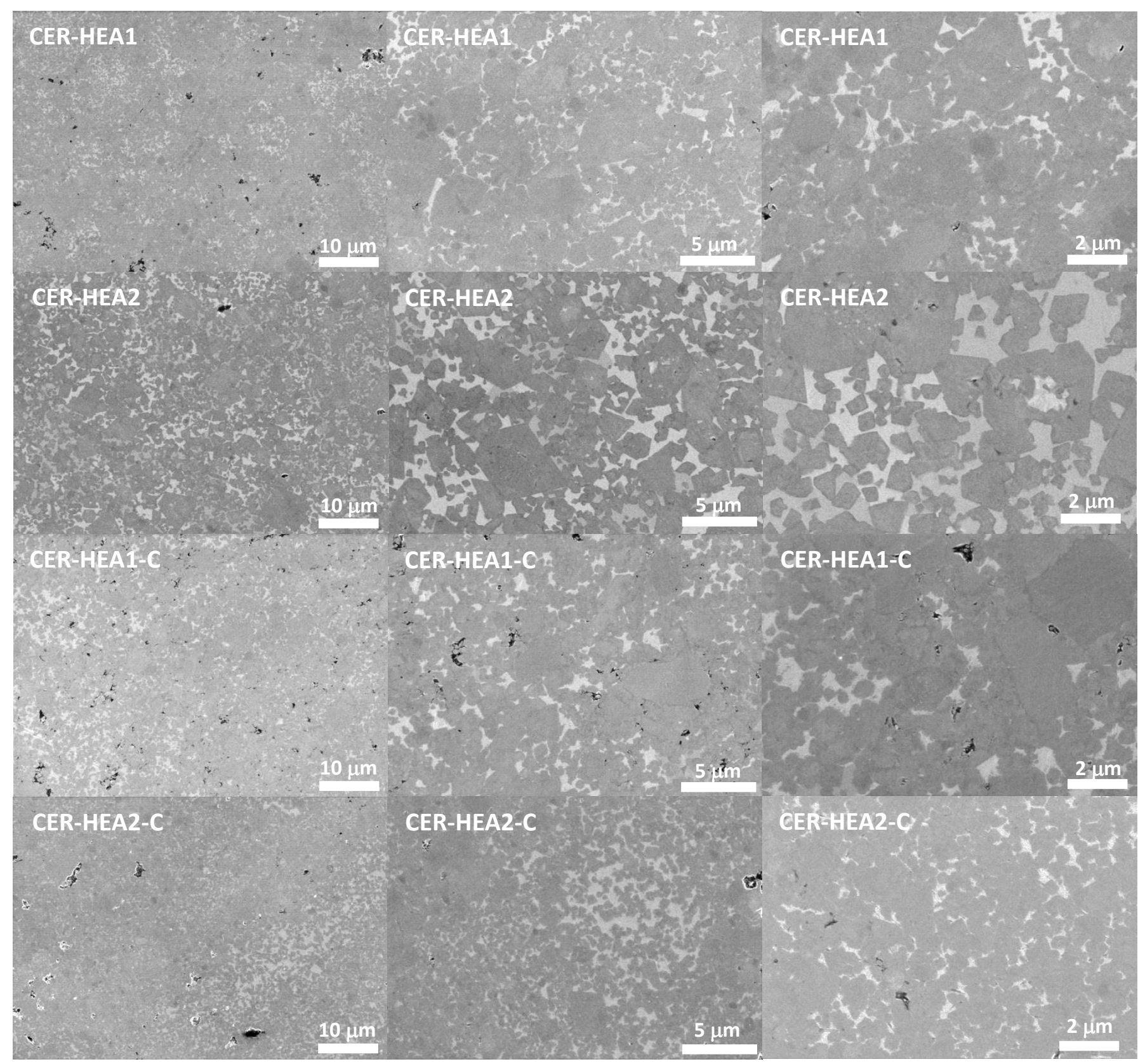

FIGURE 5 


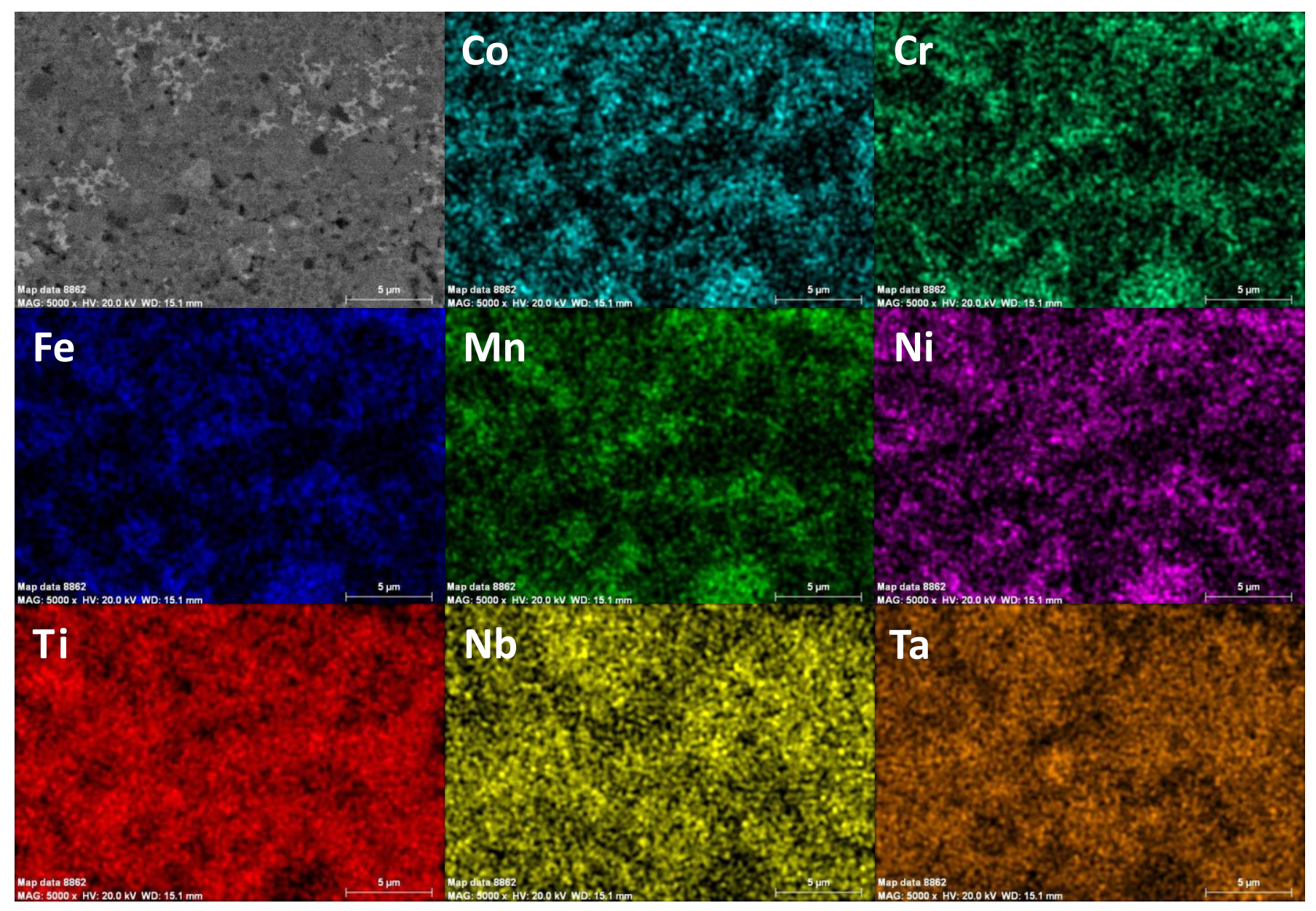

FIGURE 6 


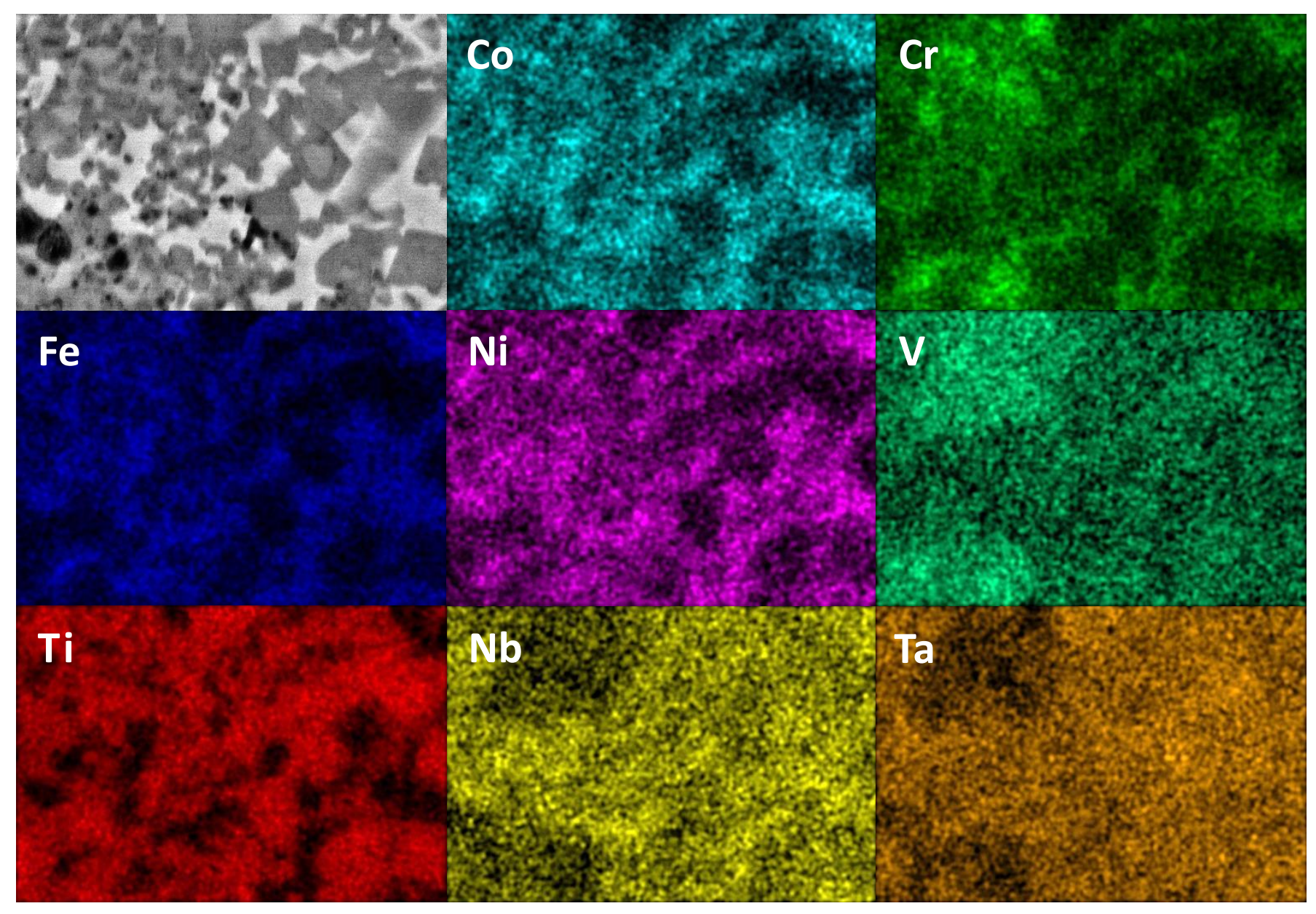

FIGURE 7 


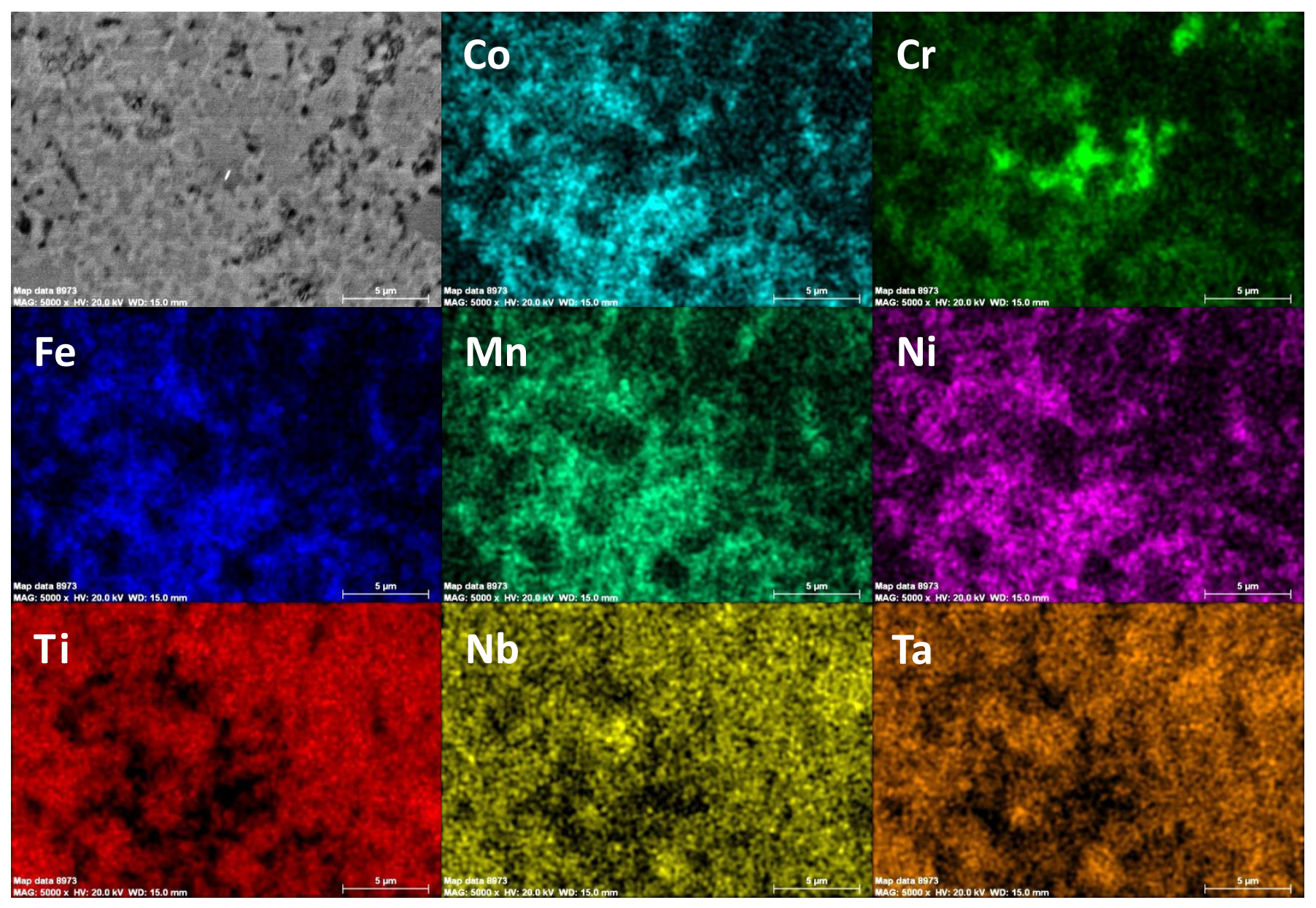

FIGURE 8 


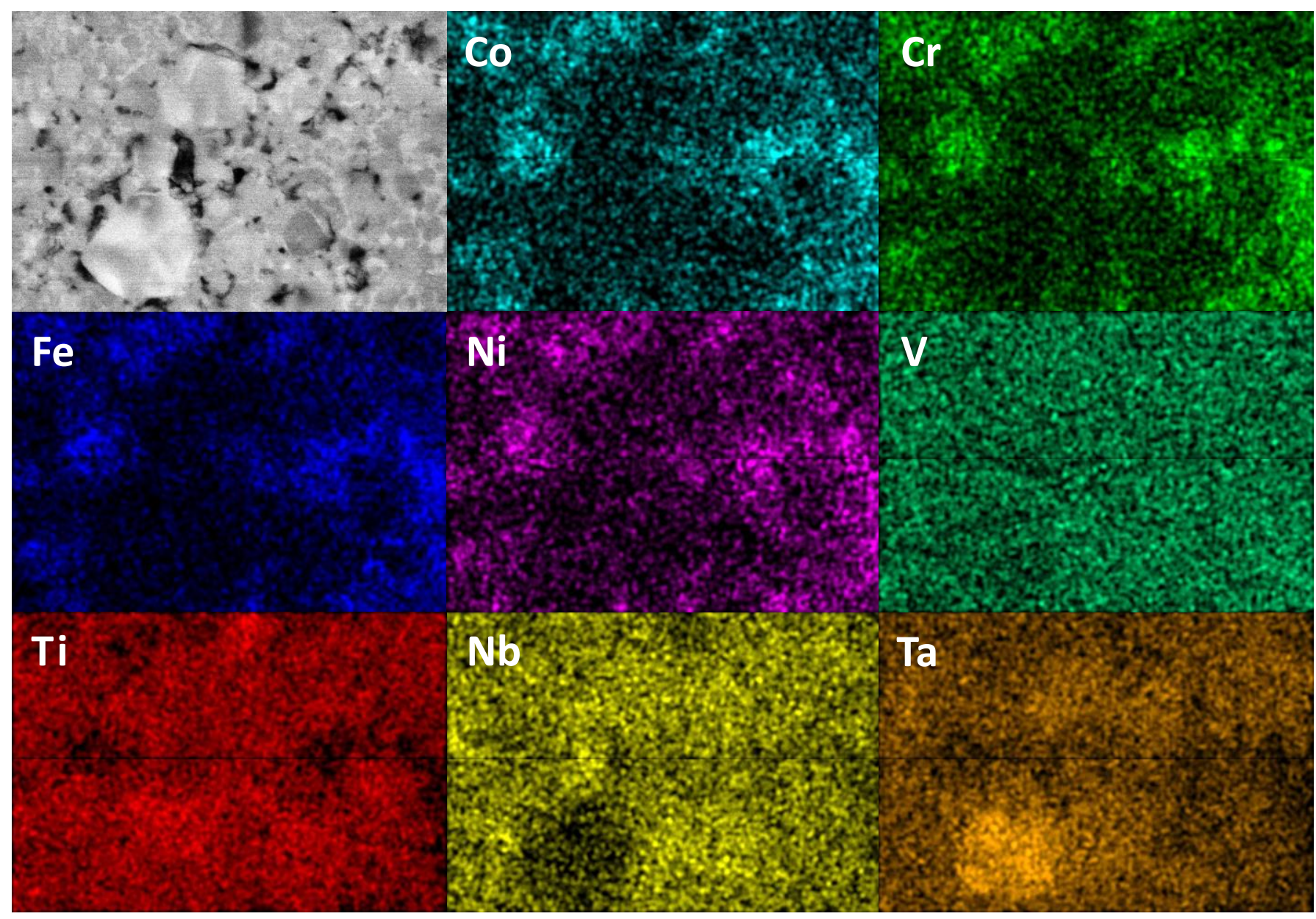

FIGURE 9 